\title{
Evaluating Variable Which is Influencing Online Repurchase Intention to Increase Fresh Vegetables/Fruits Consumption in Indonesia by Using Importance Performance Analysis
}

\author{
Amir Fikri* \\ Master of Management \\ Universitas Trisakti \\ Jakarta, Indonesia \\ *amirfikri1969@gmail.com
}

\author{
Megawati Simanjuntak \\ Department of Family and Consumer Science \\ Bogor Agricultural University \\ Bogor, Indonesia
}

\begin{abstract}
The main focus of this research is to examine the importance of online repurchase intention to increase fresh vegetables/fruits consumption based on competitiveness from behavioral aspects and the situation of e-retailer. ImportancePerformance Analysis (IPA) method is a convenient method to concurrently take into account the importance and performance dimensions when defining and evaluating strategy. This technique has been successfully employed in various settings to define priorities and guide decision-making on resource allocation. This study uses IPA to evaluate online repurchase intention strategies on fresh vegetables/fruits e-retailers and to draw recommendations for resource allocation. This research can provide input for marketing managers in e-retailer, especially fresh vegetables/fruits e-commerce, to make decisions related to e-shopper behavior. Strategies to increase the interest in repurchasing fresh vegetables/fruit are based on the priority of indicator improvement using importance-performance analysis charts. This study applies a convenience sampling technique to select study participants, which results in 331 respondents who met the following criteria: people who knew, tried, or used fresh vegetable/fruits e-commerce, and live in five designated regions in Indonesia. The results of this study show that 'rushing' situation causes of unfavorable activities, price fairness, the gentleness of employees, and quality assurance are important attributes for the customers which have not fulfilled by the modern retail management. Those attributes could be the main concern for modern retail management to increase the competitive factors so that repurchase intention will increase as well.
\end{abstract}

Keywords-importance-performance analysis, repurchase intention, e-retailer

\section{INTRODUCTION}

At present, the use of the internet continues to grow. Based on internet penetration data collected through a survey conducted in 2017 by the Association of Indonesian Internet Service Providers (APJII), the number of internet users in Indonesia in 2017 was 143.26 million users or around $54.68 \%$ of the total population of Indonesia [1]. In its development, the internet now not only functions as a medium of information and communication media but is also used as a means for selling or shopping.

The internet has encouraged the use of internet-based communication technology for marketing, especially marketing agricultural products. The trend of shopping through the internet is the main attraction for consumers to shop quickly, safely, comfortably, and efficiently. Online shopping is now not only shopping for fashion goods, electronics, and cosmetics as well as other items but now it has also penetrated the sale of agricultural products online.

E-commerce is one of the marketing diversification to increase profits. In addition, the application is rapidly growing following the global development of the agricultural business. However, based on APJII data in 2017, the services accessed by internet users in Indonesia with the highest percentage are used for chatting by $89.35 \%$, the lowest for accessing banking transactions by $7.39 \%$, while for purchases new goods by $32.18 \%$ [1].

Trading through internet media is commonly recognized as e-commerce. One of the services is online retailing, which has been widely known as internet retailing, e-retailing, or e-tailing [2]. It is part of interactive home shopping [3] and in broader terms also referred to as e-trade or electronic commerce [4] and e-commerce [5]. Currently, in Indonesia, there is only a few ecommerce in agriculture marketing. A business operated on ecommerce platforms is generally in the early business stage (startup) that is just developing (infant) and not much known by consumers. Some examples of e-commerce businesses in 
marketing agricultural products include rego pantes, vegetable boxes, five kilos, farm hubs, and others.

Efforts to use e-commerce are expected to cut the marketing chain of fresh vegetables/fruit so that they are increasingly able to increase public interest in shopping as end consumers through online means. By promoting the spirit of increasing the competitiveness of local products by reducing the distribution chain of agricultural products, e-commerce helps marketing fresh vegetables/fruit through online media and also increases access to purchasing services by internet users in the future.

This study aims to identify the attributes that need to be improved in modern retail, relating to the environment and shopping situation using the IPA method.

\section{LITERATURE REVIEW}

\section{A. Importance of Performance Analysis}

Martilla and James [6] introduced Importance Performance Analysis as a framework for understanding customer satisfaction as a function of both expectations related to salient attributes and judgments about their performance. While each yields valuable information independently, the full potential and promise of this type of information are more likely to be realized when the two concepts are merged [7]. By identifying attributes that should be emphasized or de-emphasized, IPA guides the prioritization and development of action plans to minimize mismatches between importance and performance [8], resulting in improved operational efficiencies through resource redeployment recommendations [9]. The importanceperformance analysis begins with identifying the critical elements to be evaluated [10]. Typically, this list is based on a thorough literature review or qualitative research [8]. In this study, the critical elements are small firms' motivations for engaging in e-business (subsequently discussed). Importance and performance ratings were obtained on each element from the sample using a survey instrument, which in many cases, employs Likert or other similar numerical scales [8].

The current literature on the simultaneous consideration of importance and performance has taken after two methodological streams, namely gap analysis and importanceperformance (IP) maps. The gap analysis focuses on identifying performance gaps, which are typically measured by subtracting performance from importance [7,11]. Using this method, negative scores that represent the underperformance on 16 of 18 attributes of online services offered by a university library were identified [11]. In another study, a gap analysis was also applied by Shaw et al [7] to analyze the service quality of IS/IT systems. Shaw et al [7] suggested that gap analysis is thoroughly grounded can be suitably incorporated in an IS context. Conversely, other scholars have argued that this method has some considerable limitations that could misguide the result as well as the interpretation (e.g., [12]).

The second approach, importance-performance (IP) maps, involves plotting the mean ratings for importance and performance on a two-dimensional grid to produce a fourquadrant matrix. The matrix serves both information on areas requiring improvement and areas of effective performance [8]. As shown in Figure 1, quadrant I (High Importance/Low Performance) is marked as "Concentrate here." Elements located in this quadrant indicate key challenges that need prompt corrective action and thus should be given top priority [13]. Quadrant II (High Importance/High Performance), marked as "Keep up the good work," contains elements that are strengths to the organization and demand preservation in its quality [13]. If elements positioned in quadrant III (Low Importance/Low Performance), labeled as "Low priority," do not refer to a threat to the organization [14], they may be candidates for discontinuation of resources/effort [15]. Finally, elements that indicate insignificant strengths to the organization are located in quadrant IV (Low Importance/High Performance). Quadrant IV is labeled as "Possible overkill," which covers areas where resources could be allocated to other areas.

As the quadrant approach is extended, the diagram is incorporate an upward inclining $45^{\circ}$ line to distinguish areas with different priorities. Termed as the iso-rating or iso-priority line, it portrays importance corresponding to performance. Skok et al [8] defines the area above the line as the region of opportunities and suggest that large gaps identify areas of priority. Slack [9] used this line to identify the lower limit of acceptability, with elements above the line calling for improvement. Bacon [12] contends that points falling on the line have the same needs for improvement, whereas points above the line indicate high improvement in need. Thus, the iso-rating line, where performance equals importance, represents optimal points on the IP map. Given that the positions of the attributes on the grid determine everything, Martilla and James [6] suggests that placement of the axes is critical [15]. In this regard, a number of methods can be used to assign where the axes are posited, including values [15], scale midpoints [8], and weighted mean for importance [16]. However, among all of these values, the place of assignment based on means is generally used $[11,17]$.

IPA had been utilized to investigate differences in viewpoints among the subcomponent of the organization's markets [7] and constituents [8]. Further, Skok et al [8] noted that the significance and reliability of importance-performance analysis had been extensively examined.

Prior researchers have suggested IP mapping as a valuable analytical tool to promote common management decisions due to its simplicity, flexibility, and visual approach $[10,12]$. IP maps may provide assistance to business managers in determining resource distributions since attributes are located in quadrants according to their priorities [9]. Further, this allows the deployment of organizational resources to be improved [9] because of the reduced conflicts between importance and performance $[8,13]$. Thus, IPA and, in particular, IP maps equip business managers with an effective tool to lead the resource prioritization and allocation. 


\section{METHODS}

The research approach used is descriptive quantitative using online survey methods to fresh vegetables/fruits online shoppers. Data collection took place for a month from November to December 2018. Respondents in this study represent consumers who use e-commerce platforms to purchase fresh vegetables/fruits online. Also, respondents are limited to e-commerce users living in Jakarta, Depok, Bogor, Tangerang, and Bekasi.

The sampling withdrawal method applied in this study is convenience sampling, which is part of non-probability sampling. If the population is unknown, Hair et al [18] recommends a minimum sample size of 5-10 times the variable coefficient. The minimum sample in this study amounted to 331 respondents. This study uses primary data in the field. Data were collected by an online method using Google form survey. The online survey method is spread through social media, namely email and WhatsApp. Data collected in the form of primary data from respondents in the form of information that includes research variables. The instrument incorporated in this study, namely an online questionnaire with the help of Google Docs. The questionnaire is divided into three main parts, namely, screening, profiling, and the main questions related to research indicators. The online questionnaire was distributed in the form of Google Docs links through various social media applications. Types of questions in research using closed questions.

In this study, a five-point Likert scale is used to measure indicator variables. According to Oei [19], the Likert scale is a scaling method measuring the degree of agreement or disagreement of respondents to a series of statements that assess an object. The Likert scale provisions in this study are: Strongly disagree coded as 1; Disagree coded as 2; Quite agree as 3; Agree coded as 4; Strongly agree coded as 5 .

Test the validity and reliability of the instrument used to ensure that the measuring instrument has reflected in accordance with the circumstances and is consistent. Validity is described by Pearson's correlation coefficient, while reliability is represented by Cronbach's Alpha values. The data analysis technique used is the Importance-Performance Analysis (IPA) method, which shows the relationship between the level of importance and the level of performance. The level of importance on the $\mathrm{Y}$-axis is measured based on the assessment of the loading factor from the calculation of the Structured Equation Model (SEM) method, while the level of performance on the $\mathrm{X}$-axis is measured based on the average value given by each respondent on each indicator. The dividing line for the level of importance is calculated based on the average value of the loading factor, while the dividing line for the level of performance is calculated based on the average rating of respondents on each indicator. Each attribute or level of importance and performance level is described in a diagram like in Figure 1.

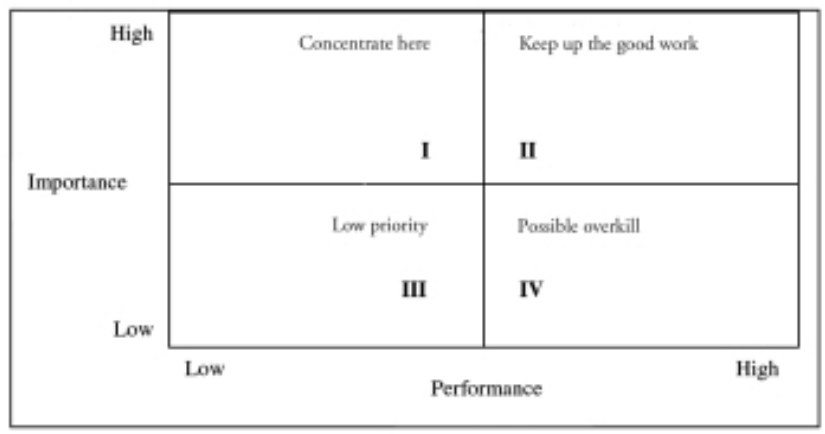

Fig. 1. Importance-performance analysis diagram [6].

A Cartesian diagram was used to map indicators of independent variables with the following information:

- Quadrant I: Indicates indicators that are considered very important, but not following the wishes of the customer so disappointing (Top Priority)

- Quadrant II: Indicates indicators that are considered very important, and performance is good (maintained).

- Quadrant III: Indicates indicators that are considered a less important influence on customers or are considered less important and show less good performance (Low Priority).

- Quadrant IV: Indicates indicators that are considered a less important influence, but the performance is excessive or is considered less important, but the performance is excessive (excessive)

\section{RESULTS}

\section{A. Characteristics of Respondents}

The results of this study showed that the majority of respondents were female, with a percentage of $74.4 \%$ of the total respondents. Male respondents composed the remaining $25.6 \%$ of the total respondents. Gen Y (born 1981-1994) dominates the participants of this study, with a percentage of $46.8 \%$ of respondents. The majority of respondents owned a bachelor's degree $(55.6 \%)$. The result indicates that $58.6 \%$ of the respondents were married, and $58 \%$ of the respondents worked as private sector employees. In terms of the region of domicile, more than half of the respondents were living in Jakarta $(61.3 \%)$ at the time of data collection.

\section{B. Shopping Behavior of Respondents}

From this study, fresh vegetable/fruit e-shopper was dominated by the socioeconomic status of $\mathrm{A}$ as much as $76.7 \%$, with buying behavior when needed alone as much as $63.7 \%$; online transaction media use smartphones as much as $89.7 \%$. There were $77.9 \%$ of respondents bought fruits, and the remaining proportion of respondents bought vegetables; the respondents were more familiar with vegetable boxes as ecommerce providers of fresh vegetables and fruit as much as 28.7\%; respondents know e-commerce of fresh fruit vegetables 
through social media as much as $44.7 \%$; shopping expenditure per transaction between Rp100,000 and Rp150,000 (37.2\%).

This research can provide input for marketing managers in online shop companies, especially fresh vegetable/fruit ecommerce, to make decisions related to e-shopper behavior.
Strategies to increase the interest in repurchasing fresh vegetables/fruit are based on the priority of indicator improvement using importance-performance analysis charts [20]. The Cartesian diagram is used to map indicators of independent variables in Figure 2.

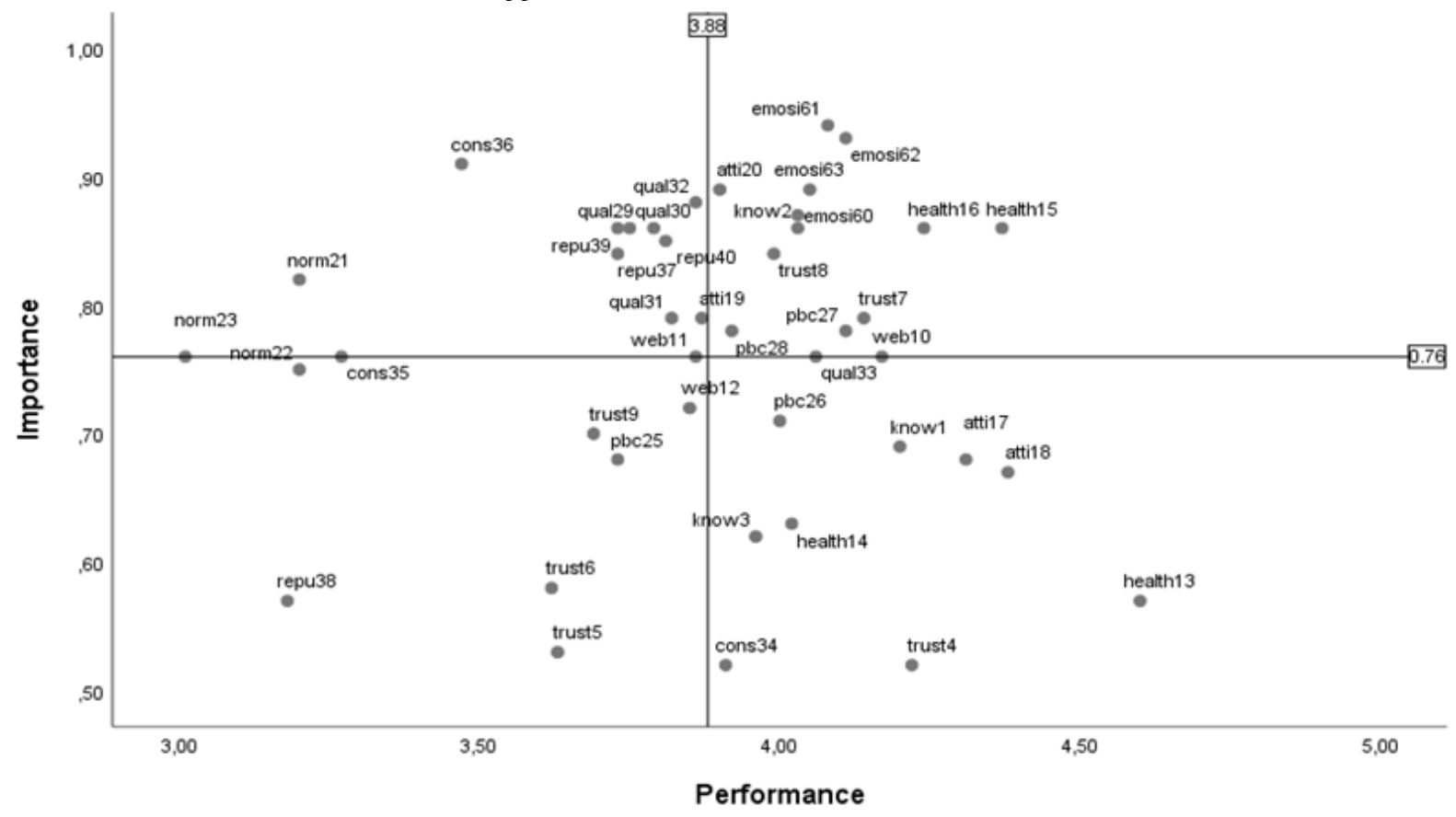

Fig. 2. Performance analysts are based on independent variable indicators

Quadrant I shows an indicator that is considered very important, but not in accordance with the wishes of the eshopper so disappointing (top priority). In this quadrant contains indicators that are considered important by e-shopper, but not in line with e-shopper expectations. Indicators that enter the first quadrant are indicators that must be improved. Based on Figure 2, the influence of friend influence (norm21), endorser influence (norm23), high quality (qual29), always fresh (qual30), high quality (qual31), have good color, taste, and texture (qual32), relative price is not expensive (cons36), managed by a reliable company (repu37), has a good reputation (repu39) and professional management (repu40) is an indicator that falls into the first quadrant. That is, to increase interest in repurchasing fresh vegetables/fruit online, the e-retailer needs to improve these indicators.

Quadrant II: Indicates indicators that are considered very important, and performance is good, so it needs to be maintained because it meets e-shopper expectations. Based on Figure 2, indicators included in the second quadrant are knowledge that there are more benefits in shopping online (know2), must be sent after being paid (trust7), products are received to order (trust 8), health-conscious consumers (health15), style awareness healthy life (health16), like because of a sense of security and comfort in shopping (att20), independence (pbc27), ability to overcome difficulties (pbc28), make joy (emotion 60), fun (emotion 62) and pleasure shopping/joyful (emotion 63). That is, these indicators are strengths that need to be maintained by e-retailer management. If the power fails to be maintained, then the indicator becomes the main priority that needs to be developed.

Quadrant III: Indicates indicators that are considered a less important influence on e-shopper or are considered less important and show less good performance (low priority). Based on Figure 2, indicators included in the third quadrant are no data leakage/not hacked (trust6), security of personal data and not traded (trust5), no fraud (trust9) family influence (norm22), contain significant information (web12), is well known to many people (repu38), and there are resources to make purchases (pbc25). That is, if the indicator fails to be maintained, then the e-shopper will continue to have a repurchase interest, so this will not be a threat to e-retailer management.

Quadrant IV: Indicates indicators that are considered a less important influence, but the performance is excessive or considered less important, but the performance is excessive (excessive). This quadrant contains excessive-performance indicators so that the allocation of resources should be used to improve improvements to the attributes of the first quadrant. Based on Figure 7, the attributes included in the fourth quadrant are the existence of e-commerce (know1), know the disadvantages/disadvantages of online shopping (know3), trust 
in the payment and transaction processes (trust4), like because it is practical (atti17), vegetables/fruit important for health (health13), impact on health (health14), like because it saves time (atti18), is entirely up to the respondent (pbc26), and the price is proportional to how it looks (cons34). This means that in general, these indicators have met e-shopper expectations, so there is no need for continuous development. The allocation of resources to foster repurchase interest in this aspect should be used to develop the indicators contained in the first quadrant.

\section{CONCLUSION}

The use of the Importance-Performance Analysis (IPA) method is useful to give priority to the improvement of attributes in e-commerce based on the level of assessment of eshoppers. Indicators that need to be improved are cons36, norm21, norm23, qual2, qual30, Qual31, qual32, repu37, repu39, repu40. Improvements to these aspects are very important if e-retailer want to maintain their business presence in the current online retail business competition.

\section{REFERENCES}

[1] Association of Indonesian Internet Service Providers, Survey 2017: Penetrasi dan perilaku pengguna internet Indonesia, [Online]. Available from: https://apjii.or.id/content/read/39/342/Hasil-Survei-Penetrasi-danPerilaku-Pengguna-Internet-Indonesia-2017, 2018.

[2] L. Anderson, Retail and wholesale industry. Hoover's [Online] [Accessed on 2018 June 6], 2000.

[3] J. Alba, J. Lynch, B. Weitz and C. Janisqewski, "Interactive home shopping: Consumer, retailer, and manufacturer incentives to participate in electronic marketplaces," Journal of Marketing, vol. 61, no. 3, pp. 3853, 1997.

[4] E. Daniel and G. M. Klimis, "The impact of electronic commerce on market structure:: An evaluation of the electronic market hypothesis," Eur. Manag. J., vol. 17, no. 3, pp. 318-325, 1999.

[5] R. Boscheck, "New media economics are transforming consumer relations,” Long Range Plann., vol. 31, no. 6, pp. 873-878, 1998.
[6] A. John, "Martilla and John C. James,(1977). Importance-Performance Analysis," J. Mark., vol. 41, no. 1, pp. 77-79, 1977.

[7] N.C. Shaw, W.H. DeLone, and F. Niederman, "Sources of dissatisfaction in end-user support: An empirical study," Database for Advances in Information Systems, vol. 33, no. 2, pp. 41-56, 2002.

[8] W. Skok, A. Kophamel, and I. Richardson, "Diagnosing information systems success: importance-performance maps in the health club industry," Inf. Manag., vol. 38, no. 7, pp. 409-419, 2001.

[9] N. Slack, "The importance-performance matrix as a determinant of improvement priority,” Int. J. Oper. Prod. Manag., 1994.

[10] C.R. Duke and A.S. Mount, "Rediscovering performance-importance analysis of products," J. Prod. Brand Manag., 1996.

[11] M. O'Neill, C. Wright, and F. Fitz, "Quality evaluation in on-line service environments: an application of the importance-performance measurement technique," Manag. Serv. Qual. An Int. J., 2001.

[12] D.R. Bacon, "A comparison of approaches to importance-performance analysis," Int. J. Mark. Res., vol. 45, no. 1, pp. 1-15, 2003

[13] L.A. Graf, M. Hemmasi, and W. Nielsen, "Importance-satisfaction analysis: a diagnostic tool for organizational change," Leadersh. Organ. Dev. J., 1992

[14] J.D. Barsky and R. Labagh, "A strategy for customer satisfaction," Cornell Hotel Restaur. Adm. Q., vol. 33, no. 5, pp. 32-40, 1992.

[15] J.L. Crompton and N.A. Duray, "An investigation of the relative efficacy of four alternative approaches to importance-performance analysis,” J. Acad. Mark. Sci., vol. 13, no. 4, pp. 69-80, 1985.

[16] L.D. Arthur, "A Consumer Complaint Framework with Resulting Strategies. An Applicationto Higher Education,” J. Serv. Mark., vol. 8 no. 3, pp. 27-39, 1994.

[17] K. Weber, "Meeting Plantners' Perceptions of Hotel-chain Practices and Benefits: An Importance-Performance Analysis," Cornell Hotel Restaur. Adm. Q., vol. 41, no. 4, pp. 32-38, 2000.

[18] J.F. Hair, W.C. Black, B.J. Babin, R.E. Anderson, Multivariate Data Analysis. 7th ed. New Jersey: Prentice Hall, Upper Saddle River, 2010.

[19] I. Oei, Riset Sumber Daya Manusia. Jakarta: PT Gramedia Pustaka Utama, 2010

[20] C.Y. Wong, S. Boon-Itt, and C.W.Y. Wong, "The contingency effects of environmental uncertainty on the relationship between supply chain integration and operational performance," J. Oper. Manag., vol. 29, no. 6, pp. 604-615, 2011 